\title{
Annular skin lesions in childhood: Review of the main differential diagnoses
}

\author{
Diana Narváez, Beatriz Di Martino Ortiz, Mirtha Rodríguez Masi
}

Department of Dermatology, Clinicas Hospital, Faculty of Medical Sciences, National University of Asuncion, Paraguay

Corresponding author: Prof. Dr. Beatriz María Di Martino Ortiz, E-mail: beatrizdimartino@gmail.com

\begin{abstract}
Figurate skin eruptions are fixed or migratory lesions, which is clinically characterized by annular circinate, arcuate, targetoid or polycyclic plaque. Although most skin lesions typical annular are dermatophytosis (ringworm), general practitioners and especially pediatricians have to consider other possible diagnoses. Tinea corporis often can be diagnosed based on a direct positive test with potassium hydroxide. Topical and systemic antifungal are usually curative. Pityriasis rosea is characterized by small lesions, light erythematosus colored, distributed along the lines of division of the skin. Treatment is symptomatic. Granuloma annulare is characterized by annular plaques with non-squamous indurated edges, usually in the extremities. Half of the cases resolve spontaneously within two years. Hansen's disease may present with similar body ringworm plates by submitting one or more annular lesions. Urticaria, that may affect 10 to 20 percent of the population, is presented with evanescent annular plates with no scales. The subacute cutaneous lupus erythematosus may occur in a ring on sun-exposed areas as well as Papulosquamous form. Erythema annulare centrifugum typically presents annular shaped scaly patches on the edges of the erythematous plaques. In all cases both findings, clinical and histopathological should be considered when it comes to annular lesions which are frequently seen in daily routine.
\end{abstract}

Key words: Figurate erythema; Erythema anular; Granuloma annulare; Tinea corporis; Centrifugal annular erythema

\section{INTRODUCTION}

Annular lesions are extremely common in daily clinical dermatological practice, but can be misleading for general practitioners unfamiliar with them.

The term "annular" is derived from the Latin word "ring". The lesions appear as macules (changes in skin color) circular or ovoid, or plaques (solid content lesions more than $1 \mathrm{~cm}$. of diameter in which predominate the extent and surface rather than deep) with an erythematous border and a clear center.

The most common cause of annular lesions found in the adult and child population is ringworm, which can be successfully diagnosed without a biopsy, in typical cases. However, conditions other than this, may present the same clinical appearance (Table 1).
Various mechanisms have been proposed to explain the annular configuration of lesions, not always satisfactory. One of the proposed mechanisms is based on irrigation, so that each round macula represent the territory irrigated by a single arteriole. Other authors consider that it could be centrifugal extension of a pathological process, whether infectious, neoplastic or allergic phenomenon.

\section{Tinea Corporis}

Ringworm is caused by fungi of the genus Microsporum, Trichophyton and Epidermophyton. The transmission thereof occurs by direct contact from person to person, from animals to humans and from the soil to animals and/or humans, depending if you try to anthropophilic, zoophilic or geophilic species [1]. 
Table 1: Main annular lesions that occur in childhood

\begin{tabular}{|c|c|c|c|}
\hline Diagnosis & Clinical features & Histopathology & Treatment \\
\hline Tinea corporis & Erythematous annular plates. & $\begin{array}{l}\text { Psoriasiform epidermal acanthosis. } \\
\text { Intracorneal pustules. PAS+for hyphae. }\end{array}$ & Topical or systemic antifungals. \\
\hline Pityriasis rosae & $\begin{array}{l}\text { Small salmon plates, with scales on the } \\
\text { edges, along the lines of division of the } \\
\text { skin. One is higher (herald). }\end{array}$ & $\begin{array}{l}\text { Irregular epidermal acanthosis, } \\
\text { spongiosis, diskeratosis (in heraldic } \\
\text { plate), dermal hematic extravasation. }\end{array}$ & Topical or systemic corticosteroids; UVA; UVB. \\
\hline Granuloma annulare & $\begin{array}{l}\text { No scaly skin color patches, with raised } \\
\text { indurated edges, extremities. }\end{array}$ & $\begin{array}{l}\text { Necrobiosis area of dermal collagen } \\
\text { surrounded by a palisade of } \\
\text { inflammatory cells. }\end{array}$ & $\begin{array}{l}\text { Spontaneously resolution or after biopsy. } \\
\text { Topical or intralesional corticosteroids. }\end{array}$ \\
\hline Hansen $\times s$ disease & $\begin{array}{l}\text { Hypochromic macules or erythematous } \\
\text { plaques without scales. The edges will be } \\
\text { more or less defined depending on the type } \\
\text { of Hansen. }\end{array}$ & $\begin{array}{l}\text { Lymphocytic }(\mathrm{HI}) \text {, granulomatous (HT, } \\
\text { HBT) or macrophage (HBB, HBL, } \\
\text { HL), periadnexal, perivascular and } \\
\text { perineural infiltrate. } \mathrm{ZN+for} \mathrm{BAAR.}\end{array}$ & Dapsone, rifampicin, clofazimine. \\
\hline Urticaria & $\begin{array}{l}\text { Evanescent not scaly erythematous wheals. } \\
\text { Absence of skin alterations. }\end{array}$ & $\begin{array}{l}\text { Perivascular dermal edema. Extra and } \\
\text { intravascular neutrophils. Perivascular } \\
\text { eosinophils. Mild leukocytoclasia. No } \\
\text { vasculitis. }\end{array}$ & Oral antihistamines \\
\hline $\begin{array}{l}\text { Centrifugal anular } \\
\text { erythema }\end{array}$ & $\begin{array}{l}\text { Annular plate with scale leaves the } \\
\text { erythematous border. }\end{array}$ & $\begin{array}{l}\text { Superficial and deep perivascular } \\
\text { dermal lymphocytic infiltrate. Variable } \\
\text { skin alterations. }\end{array}$ & $\begin{array}{l}\text { Topical or systemic corticosteroids. Oral } \\
\text { antihistamines. Treating the underlying cause. }\end{array}$ \\
\hline $\begin{array}{l}\text { Subacute cutaneous } \\
\text { lupus erythematosus }\end{array}$ & $\begin{array}{l}\text { Papulosquamous annular plates, with or } \\
\text { without scales, in sun-exposed areas. }\end{array}$ & $\begin{array}{l}\text { Vacuolar interface dermatitis with } \\
\text { apoptotic keratinocytes. Pigmentary } \\
\text { incontinence. Superficial perivascular } \\
\text { lymphocytic infiltrate. Mucin. }\end{array}$ & Topical, systemic or intralesional, antimalarials. \\
\hline
\end{tabular}

It is characteristic in the skin of the trunk and extremities, restricted to the stratum corneum and most commonly occurs on exposed skin, although it can develop anywhere on the body.

It is most common in tropical regions like our country. Pets are an important factor in transmission, especially those zoophilic species. The incubation period is 1 to 3 weeks. The infection spreads centrifugally from the point of skin infection with a clear center, resulting in typical erythematous annular lesions of different sizes, with well circumscribed scaly, papular, vesicular or pustular edge. As they increase in size, the plates may have concentric rings (Fig. 1) [2,3].

Topical and oral imidazols are the treatment of choice for ringworm. General measures are indispensable, such as avoiding moisture or maceration of the skin, weight loss and the use of cotton clothes [4,5].

\section{Pityriasis Rosea}

Common skin disease of children and young adults characterized by been a self-limited disease. It is usually preceded by upper tract respiratory symptoms [6].

Initially a heraldic plaque or mother plaque, typically located in the trunk, between 2 and $10 \mathrm{~cm}$ of diameter appears. The plaque is oval, erythematous, with a collarette desquamation on the periphery. After days, others plaques appear, similar in appearance to heraldic plaque but smaller in size, between 5 and $10 \mathrm{~mm}$ in

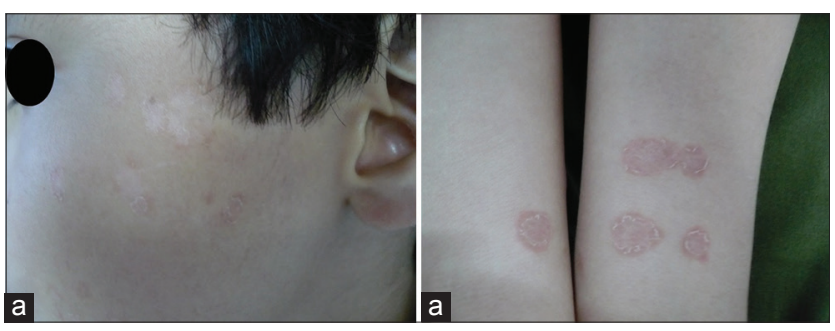

Figure 1: a) Tinea faciei, b) Tinea corporis. Erythematous annular lesions of different sizes, with well circumscribed scaly in the face and arms.

diameter distributed throughout the trunk and less commonly in extremities, along the lines of division of the skin. If they are located on the back take on the appearance of a Christmas tree.

Skin biopsy usually is not indicated in these patients, although in borderline cases is performed. It shows a spongiform- subacute pattern with chronic non-specific inflammatory infiltrate, with apoptotic keratinocytes in the epidermis (especially in heraldic plaque). The picture is resolved between five to eight weeks from the beginning [4].

Rarely needs treatment, but if patients have accompanying pruritus, emollients such as zinc oxide, calamine lotions, and topical low power corticosteroids can be used [7]. Systemic antihistamines can also be used. In more severe cases treatments with ultraviolet light and natural sun exposure are described $[4,8]$. 


\section{Granuloma Annulare}

Self-limiting inflammatory entity of unknown etiology, characterized by annular skin color or slightly erythematous plaques, with elevated periphery and depressed center (Fig 2a and 2b), possibly result of non-specific reactions from various agents [9-11].

Located more often in the hands, feet, wrists and ankles, they can be located anywhere in the body. These lesions are usually asymptomatic, although some patients report mild itching. It is more frequent in females, predominantly in children and young adults. Four clinical forms are described: classical or localized, generalized, perforating and subcutaneous [12]. It have been linked to certain triggers such as: vaccination, insect bites, contact dermatitis to nickel, solar exposure, intestinal parasites and Ebstein-Barr virus, HIV, Herpes zoster virus infections among others. Is thought to be the result of vasculitis, necrobiosis secondary to trauma, activation of monocytes, Langerhans cell or a T cell phenomenon of type IV hypersensitivity. Some even believe there is a Koebner phenomenon [13].

Three histological varieties are distinguished: granulomatous (palisade), interstitial (incomplete) and deep (nodular) forms (Fig. 2c). They differ only in the location of granulomas. The granulomatous form is characterized by a palisade of histiocytes around degenerated collagen area where it can be mucin shown with special stains (Alcian blue or colloidal iron). It can be seen eosinophils and lymphocyts in the inflammatory infiltrate. In interstitial variant, macrophages are disposed between the collagen bands without forming palisade granulomas. The nodular form is characterized by deep subcutaneous granulomas with necrobiosis, but clinical presentation is not annular, it's nodular [14].

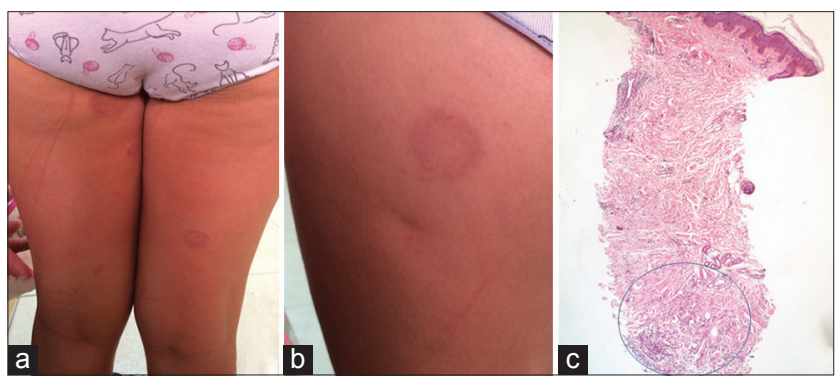

Figure 2: Granuloma annulare. (a and b) No scaly skin color patches, with raised indurated edges in lower extremities. (c) Necrobiosis area of dermal collagen surrounded by a palisade of inflammatory cells.
The diagnosis is made by clinical and histopathologic correlation. In the absence of fever or other symptoms it is not necessary to request additional tests. Some of the patients with granuloma annulare can present hyperlipidemia, hipergammaglobulineamia and circulating antinuclear antibodies. It can be ordered fasting and postprandial and determinations of glycated hemoglobin in patients with a family history of diabetes [4].

There is no successful treatment of the disease. Up to $50 \%$ of patients with localized forms may have spontaneous resolution in two years with a likely recurrence in $80 \%$ of cases, unlike the generalized form, where it is rarer and if there is not a spontaneous resolution it last at least 3 to 4 years.

In the limited forms it is not recommended any treatment. It is advisable to explain to parents the mildness of the disease, although if the therapeutic demand is strong, you can try the local treatment with topical corticosteroids, medium or high power, to avoid intralesional injection. In the deep or subcutaneous forms excision is indicated. In generalized forms dapsone (100 mg/day) can be used [4].

\section{Hansen's Disease}

Leprosy is a chronic infectious disease caused by Mycobacterium leprae; as intracellular parasite triggers an immune response in the host, with the participation of cell-mediated immunity. The development of the disease is determined by two variables: a) opportunity for exposure to mycobacteria b) the ability of immune response that the host can offer.

The household contacts are the main source of infection. It has an incubation period of between 3 and 10 years.

The diversity in clinical manifestations will be conditioned by the play of interactions between $\mathrm{M}$. leprae and the immune response offered by the host. And they may be: indeterminate, tuberculoid, dimorphic or borderline and lepromatous. Of these, the dimorphic form, which is a rare type even in childhood, is characterized by annular lesions tend to enclose areas of healthy skin and result in cut wafer images (Fig. 3). No mucous membranes or internal organs are affected. The smear is generally negative, because in the pediatric population pauci bacillary forms are the most frequent. 
The histopathology evidence lymphohistiocytic perivascular and perineural dermal infiltrates (Fig. 4). With Zeehl - Neelsen staining AAR may be displayed, but not in the indeterminate or tuberculoid forms [4]. The dimorphic leprosy should be treated with 3 drugs (multibacillary).

\section{Urticaria}

Acute urticaria, annular urticarial or acute hypersensitivity syndrome represents an allergic hypersensitivity reaction mediated by histamine after viral or bacterial infections or after consumption of food or drugs. It is frequent in infants and children aged between 4 months and 4 years.

Most authors believe that this is not a single entity. In early childhood is often misdiagnosed as erythema multiforme or as serum sickness disease. Clinically, it begins as a pruritic maculopapules growing rapidly to form erythematous annular, polycyclic or arcuate evanescent character (disappear in less than 24 hours).

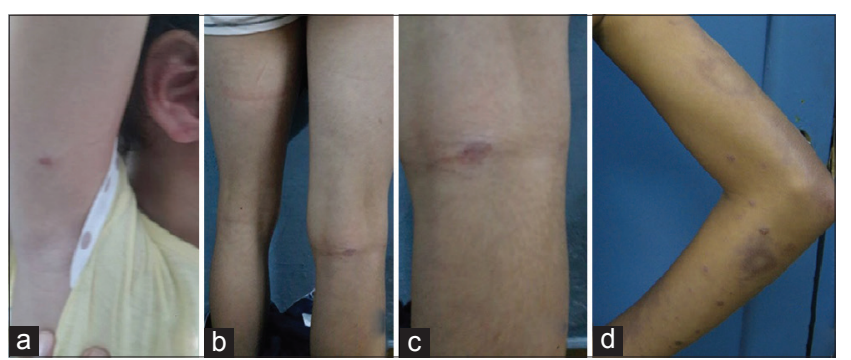

Figure 3: Hansen's disease. (a, b and c) Erythematous plaques without scales. (d) Borderline type. The plaque has a clear center in "wafer cuf".

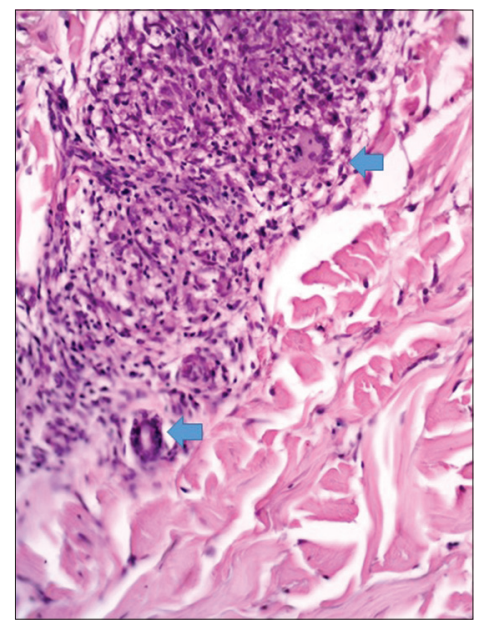

Figure 4: Histopathology of Hansen's disease. Periadnexal, perivascular and perineural infiltrate of macrophages and lymphocites. The arrows point a giant cell (as seen in tuberculoid and borderline tuberculoid types) and an eccrine duct.
It may have a central clearing or acquire a ecchymotic tone, which simulates the target lesions of erythema multiforme, but there are not epidermal necrosis, blisters or mucosal involvement (Fig. 5a).

Histologically is characterized by dermal edema, vascular dilation, presence of perivascular cellular infiltrate composed of lymphocytes, mast cells, eosinophils and neutrophils and as diagnostic key there are many intravascular neutrophils. There are no fibrin extravasation or leukocytoclasia, findings in vasculitis, despite the large number of neutrophils in biopsies. The findings are most striking in superficial dermis (Fig. 5b).

The existence of dermografism, with erythema and edema in areas of trauma, is a regular feature of urticaria. Another typical manifestations of that entity is the appearance of angioedema in the face, hands and feet. It can be confused with serum sickness disease, however in this case the individual lesions are fixed and there is no dermografism asociated $[15,16]$.

It is a self-limiting rash with resolution of episodes in about 8-10 days, with good response to oral antihistamines, reserving the use of systemic corticosteroids for more severe cases [15].

\section{Centrifugal Anular Erythema}

It is considered a hypersensitivity reaction to different antigens. Its appearance is preferably in adults, although there are also cases reported in infants and children. In the pediatric population centrifugal annular erythema is more frequently associated with Candida albicans, dermatophytes, VEB and poxvirus infections. It can also occur in relation to most common cancers in children, such as leukemia and Hodgkin lymphoma [17].

Usually asymptomatic or poorly pruritic rash remits spontaneously in about two or three weeks, reappearing in the same locations or in other different at variable

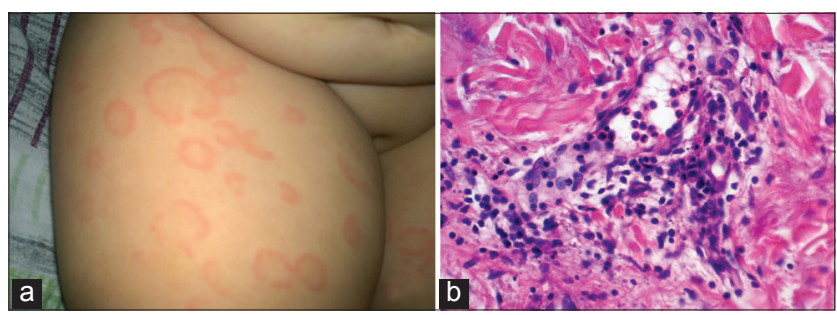

Figure 5: Urticaria. (a) Evanescent not scaly erythematous wheals. (b) Perivascular dermal edema. Extra and intravascular neutrophils. No leukocytoclasia. No vasculitis. 


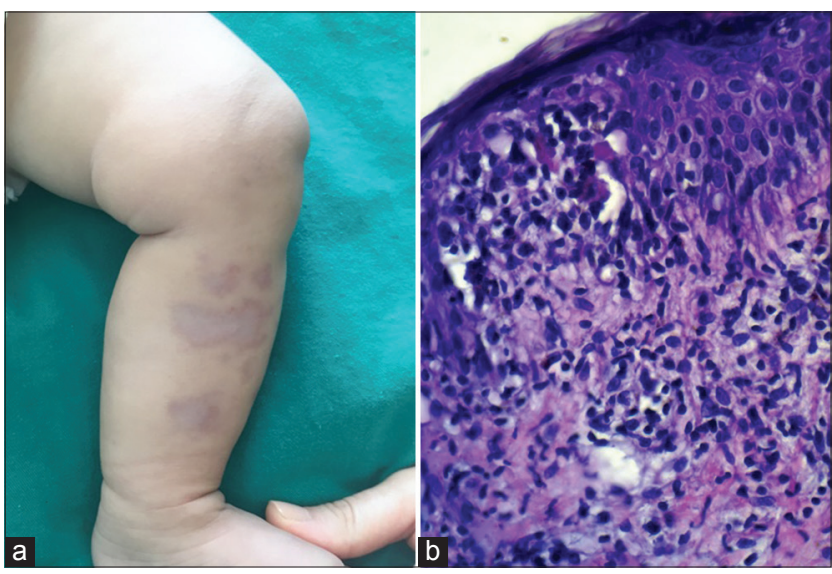

Figure 6: Neonatal lupus (sub acute form). (a) Papulosquamous annular plates, with or without scales, in sun-exposed areas. (b) Vacuolar interface dermatitis with apoptotic keratinocytes. Superficial perivascular lymphocytic infiltrate.

time intervals. Lesions, single or multiple, appear anywhere on the body, but preferably on the trunk and the root of the limbs, in the form of erythematous papules that migrates slowly $(2-3 \mathrm{~mm} /$ day $)$, flattening as it grows, fading at its center and leading to complete annular lesions or arc segments. There are two variants, one with peripheral scaly edge and intensely itchy, and the other with deeply infiltrated sharp edge without scale and asymptomatic [18].

As we already indicate, depending on the location of the perivascular infiltrate we found two variants; in the superficial type there is focal parakeratosis in the edge of the lesion, spongiosis and superficial perivascular lymphohistiocytic infiltrate, while in the deep form there is no epidermal changes, superficial and deep perivascular mononuclear cells, melanophages, slight vacuolization and necrotic keratinocytes in the dermo epidermal junction [18].

As for treatment, antihistamines are effective when there is itching, especially in children. The use of antibiotics or antifungals, in the absence of demonstrated disease, has been useful in some isolated cases, as well as administration of systemic corticosteroids [19,20].

\section{Subacute Cutaneous Lupus Erythematosus}

The subacute cutaneous lupus erythematosus may present with polycyclic annular lesions. They can accompany a commitment systemic lupus erythematosus. This variant has pronounced photosensitivity and, regression leave a hypochromia without atrophy. The periphery can have blistering or crusting.

Histopathology of these lesions shows thickening of the basal membrane, hydropic degeneration of the basal layer, and superficial lichenoid limphocytic infiltrate with melanopaghes (Figs 6a and 6b) [4].

They are very important measures designed to avoid exposure to sunlight, such as the use of sunscreens. Topical treatments include the use of corticosteroids and tacrolimus. For systemic treatment are useful hydroxychloroquine to $6.5 \mathrm{mg} / \mathrm{kp} /$ day, prior ocular control and every 4 to 6 months (color vision and visual field) or thalidomide at a dose of 50 to $100 \mathrm{mg} /$ day [4].

\section{CONCLUSION}

1. The appearance of annular lesions in childhood is always a diagnostic challenge.

2. The clinical history, appearance and characteristics of lesions by the valuable contribution of histopathology, allow us to know the different entities and separate benign self-limiting pathologies that do not require treatment of those who needed.

3. For all of the above, when we confronted a ring, annular or figurative lesion in children we paust y attention to the age of the onset injury, lesion characteristics, duration and location, evolution and histological findings to establish a diagnostic orientation and an etiological treatment.

\section{REFERENCES}

1. Bologna J, Jorizzo J, Rapini R. Dermatology. $3^{\text {rd }}$ Ed. USA: Elsevier; 2012.2:1255-65.

2. Hainer BL. Dermtophyte infections. Am Fam Physician. 2003;67:101-8.

3. Elewski BE, Nagashima - Whalen L. Superficial fungal infections of the skin $5^{\text {th }}$ Ed Philadelphia 1994: 1029-49.

4. Larralde M, Abad E, Luna P. Dermatología pediátrica. 2da Ed. Buenos Aires: Journal; 2013: p. 225-563.

5. Smith EB. The treatment of Dermatophytosis: safety considerations. J Am Acad Dermatol. 2000;43:113-9.

6. Cheong WK, Wong KS. An epidemiological study of pityriasis rosea in Middle Road Hospital. Singapore Med J. 1989;30:60-2.

7. Fitzpatrick TB, et al., eds. Dermatology in general medicine. $4^{\text {th }}$ Ed. New York: McGraw-Hill, 1993: 261-79.

8. Stulberg D, Wolfrey J. Pytiriasis Rosea. Am Fam Physician. 2004;69:87-91.

9. Hawryluk EB, Izikson L, English JC. Non-infectious granulomatous diseases of the skin and their associated systemic diseases: an evidence-based update to important clinical questions. Am J Clin Dermatol. 2010;11:171-81.

10. Cyr PR. Diagnosis and management of granuloma annulare. Am Fam Physician. 2006;74:1729-34. 


\section{www.odermatol.com}

11. Narvaez V, Vera M, Sáez de Ocariz M, Castillo M, Dominguez L. Granuloma anular en pacientes pediátricos. Dermatol Pediátr Latinoam. 2005;3:117-22.

12. Smith D, Downie J, Dicostanzo D. Granuloma annulare. Int J Dermatol. 1997;36:326-33.

13. Hsu S, Le E, Khoshevis M. Differential diagnosis of annular lesions. Am Fam Physician. 2001;64:289-96.

14. Requena L, Fernández-Figueras MT. Subcutaneous granuloma annulare. Semin Cutan Med Surg. 2007;26:96-9.

15. Chen KR, Pittelkow MR, Su D, Gleich J, Newman W, Leiferman KM. Recurrent cutaneous necrotizing eosinophilic vasculitis. A novel eosinophil-mediated syndrome. Arch Dermatol. 1994;130:1159-66.

16. Torrelo A. Urticaria y síndromes urticariales. Dermatología en pediatría general. Madrid: Aula médica; 2007. p. 251-8.

17. Cohen BA. Neonatal dermatology. Pediatric dermatology, $3^{\text {rd }}$ Ed. Philadelphia. Elsevier; 2005: 59-61.
18. Toledo-Alberola F, Betlloch-Mas I. Eritemas Anulares en la Infancia. Actas Dermo-Sifiliogr. 2010;101:473-84.

19. Freedberg IM, Eisen AZ, Wilff K, Austen KF, Goldsmith LA, Katz SI. Erythema annulare centrifugum and other figurate erythemas. Fitzpatrick's dermatology in General medicine, $6^{\text {th }}$ ed. NewYork: McGraw-Hill; 2003 p. 977-9.

20. García Muret MP, Pujol RM, Giménez-Arnau AM, Barranco C, Gallardo F, Alomar A. Annular recurring erythema annulare centrifugum: a distinct entity? J Am Acad Dermatol. 2006;54:1091-5.

Copyright by Diana Narváez, et al. This is an open access article distributed under the terms of the Creative Commons Attribution License, which permits unrestricted use, distribution, and reproduction in any medium, provided the original author and source are credited.

Source of Support: Nil, Conflict of Interest: None declared. 